\title{
Inhibition of xanthine oxidase by allopurinol: A therapeutic option for ischaemia induced pathological processes?
}

\begin{abstract}
Allopurinol was synthesised in the late 1950s to inhibit the oxidative degradation of mercaptopurine (for review see Ref 1). By that time there seemed to be no feasible way of increasing the rate of mercaptopurine conversion to thioinosinic acid, its cytotoxic nucleotide derivative. Further research focused on possible inhibition of the mercaptopurine major degradative pathway, which involves oxidation by xanthine oxidase to the inert compound thiouric acid. It was soon recognised that allopurinol could reduce the effective dose of mercaptopurine severalfold. In addition, allopurinol prevented increased serum urate concentrations and urinary uric acid excretion produced by chemotherapy, and the compound has since been almost routinely used for this purpose. ${ }^{2-4}$ Inhibition of xanthine oxidase by allopurinol is particularly useful in diseases due to or complicated by hyperuricaemia, hyperuricosuria, or urinary urate stone formation, ${ }^{5}$ with an adverse reaction rate of about $3.5 \% .^{6}$ In recent years a growing number of experimental studies have indicated that oxygen derived free radicals may be involved in the pathogenesis of diverse disease states, including chronic inflammatory polyarthritis. In this leader we examine the role of xanthine oxidase catalysed reactions in reperfusion tissue damage and summarise data already published suggesting that allopurinol may be beneficial in ischaemia mediating pathological processes.
\end{abstract}

\section{Link between xanthine oxidase and reperfusion injury}

Enhanced capillary permeability and oedema formation are subtle indicators of ischaemic injury. When ischaemia is maintained, leakage of cytosolic enzymes causes more pronounced damage, which may be manifested by microscopic or gross macroscopic changes, and will ultimately produce tissue death. A substantial body of evidence indicates that oxygen derived free radicals play a major part in producing the microvascular and parenchymal damage associated with reperfusion of ischaemic tissues. McCord et al suggested that one of the most active sources for increased intracellular generation of oxygen free radicals in tissues after ischaemia is the enzyme xanthine oxidase, ${ }^{78}$ particularly in those organs characterised by high enzyme activities, such as the small intestine and liver. ${ }^{9}$ This proposal is based on three lines of evidence: $(a)$ xanthine oxidase is a well documented biological source of oxygen radicals ${ }^{10} ;(b)$ xanthine oxidase is present in a wide variety of tissues ${ }^{9}$; and (c) allopurinol provides protection against diverse tissue injuries associated with ischaemia-reperfusion. ${ }^{8}$ This hypothesis implies the conversion of xanthine dehydrogenase to xanthine oxidase during ischaemia coupled with the availability of molecular oxygen and purine substrates, hypoxanthine and xanthine, according to the following sequence (Fig. 1): When a tissue becomes ischaemic a number of pathological events occur, including depletion of cellular stores of high energy adenine nucleotides (ATP, ADP, AMP). This leads to a build up of hypoxanthine and xanthine, which serve as oxidisable purine substrates. ${ }^{11-13}$ In addition, the cell's energy charge reduction limits the maintenance of an adequate ion gradient across its membranes. The resulting increased cytosolic calcium concentration has been proposed to activate a protease ${ }^{7}$ which converts xanthine dehydrogenase, the originally synthesised form of xanthine oxidase that accounts for about $90 \%$ of the total activity in a healthy tissue and is $\mathrm{NAD}^{+}$dependent, to xanthine oxidase which is oxygen dependent. ${ }^{14}$ When reperfusion takes place oxygen availability is restored to a tissue $(a)$ with high concentrations of oxidisable substrates (hypoxanthine and xanthine) and (b) with an enzyme that uses molecular oxygen (xanthine oxidase). After addition of xanthine to xanthine oxidase the enzyme generates superoxide radicals $\left(\cdot \mathrm{O}_{2}^{-}\right)$, which can react with superoxide dismutase 


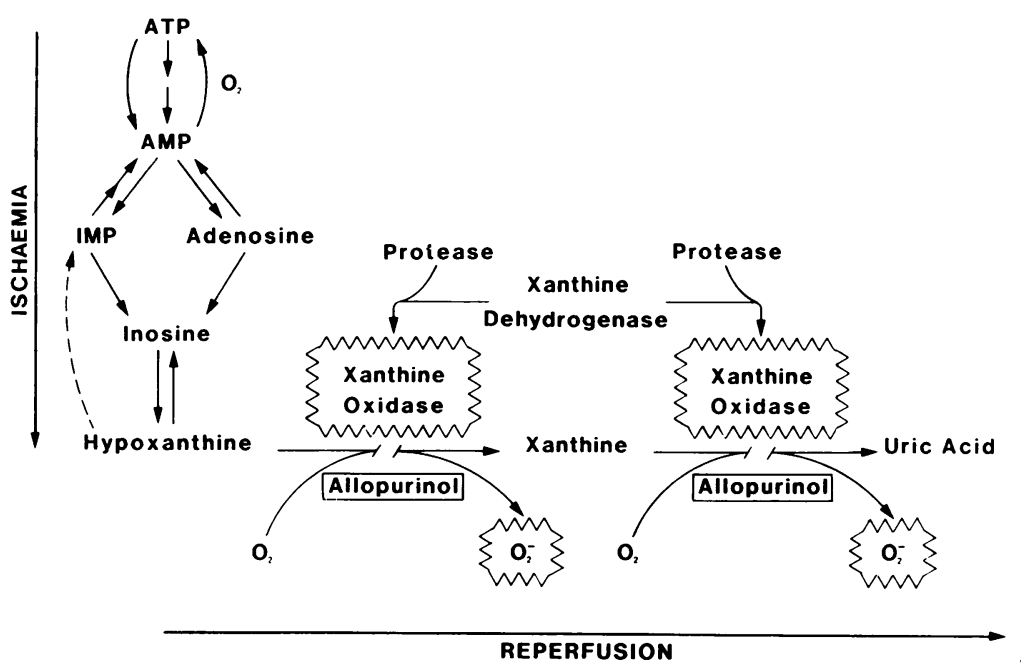

Fig. 1 Proposed mechanisms of allopurinol protection against ischaemia-reperfusion tissue damage. Allopurinol is a scavenger of hydroxyl radicals $(\cdot \mathrm{OH})$, which are formed from superoxide radicals $\left(\cdot \mathrm{O}_{2}^{-}\right)$. Inhibition of xanthine oxidase by allopurinol may limit superoxide generation. This enzymatic inhibition results in an increased availability of hypoxanthine for purine nucleotide synthesis (dashed line). In addition, allopurinol conversion to allopurinol ribonucleotide inhibits 5'-nucleotidase and prevents inosine monophosphate (IMP) and adenosine monophosphate (AMP) dephosphorylation, thereby facilitating adenosine triphosphate (ATP) synthesis. to form hydrogen peroxide $\left(\mathrm{H}_{2} \mathrm{O}_{2}\right)$ in proportions dictated by the $\mathrm{pH}$, and superoxide and xanthine concentrations. ${ }^{15}$ Superoxide and hydrogen peroxide can further generate the powerful oxidant hydroxyl radical $(\cdot \mathrm{OH})$, depending upon the presence of suitable transition metal catalysts, such as iron or copper. ${ }^{16}$ Iron metabolism has been implicated in the pathogenesis of rheumatoid arthritis. Increased concentrations of iron salts have been found in the synovial fluid of patients with rheumatoid arthritis, ${ }^{17}$ and ferritin correlates with indices of inflammatory activity. ${ }^{18} 19$

Reactive oxygen species are capable of reversibly or irreversibly damaging compounds of all biochemical classes, including nucleic acids, proteins and free amino acids, lipids and lipoproteins, carbohydrates, and connective tissue macromolecules. ${ }^{20} 21$ In addition to the xanthine oxidase system, other possible sources of oxygen radical production at the moment of reperfusion include the electron transport chain, ${ }^{22}$ leucocytes, ${ }^{23}$ and certain oxidative enzymes such as cytochrome P-450 reductase. ${ }^{24}$ Oxygen free radicals have been implicated in ischaemia-reperfusion injury in multiple tissues, including the brain, ${ }^{25}$ heart, ${ }^{26-28}$ stomach, ${ }^{29}$ small intestine, ${ }^{30}{ }^{31}$ pancreas, ${ }^{32-34}$ kidney, ${ }^{35}$ liver, ${ }^{36-39}$ muscle, ${ }^{40}$ and skin flaps. ${ }^{41}$ Evidence for this implication comes from studies in which the administration of a superoxide generating system (a purine base with xanthine oxidase and oxygen) caused tissue damage, ${ }^{42-45}$ and from controlled animal experiments in which radical scavengers attenuated tissue injury following ischaemia-reperfusion. $^{26} 30324246-48$ Recently, several authors measured directly in vitro free radical concentrations by electron paramagnetic $\frac{3}{0}$ resonance. ${ }^{49-52}$ This technique is similar to nuclear $\stackrel{\mathbb{D}}{-}$ magnetic resonance in that a sample is placed with $\overrightarrow{0}$ a magnetic field and energy is absorbed by 9 paramagnetic particle. The spectra obtained allowi distinct identification of the individual free radicat species generated. During the period of ischaemia little change in radical composition was observed ${ }^{49}$ When reperfusion started, however, a burst of free radical production ${ }^{49}$ or stable products reacting with these radicals ${ }^{50-52}$ were measured. Thereafter $\overline{\vec{c}}$ radical production decreased rapidly with time ${ }^{49} \exists$ Direct evidence of free radical production in the intact animal was recently provided by Bolli et al. ${ }^{53}$ By means of a spin trap these authors showed that the intensity of oxygen radical generation by the reperfused myocardium was related to the severity of ischaemia and was maximal two to four minutes after restoration of blood flow (90 times above ischaemic values). Thereafter the release of the trapped radical declined but continued for up to three hours after reperfusion. These studies provide $\frac{D}{0}$ direct evidence to support the hypothesis that reactive oxygen species are mainly generated within $N$ a few minutes after restoration of blood flow. ${ }^{49-53}$ This concept is particularly important in delineating $N$ possible therapeutic interventions as, to be effective, $a \mathrm{\omega}$ free radical scavenger would have to be present at the moment of reperfusion; any brief delay would probably reduce the efficacy of the agent.

The above pathogenic mechanism may be $\stackrel{\text { ? }}{+}$ applicable to the inflamed synovium. In fact several clinical observations have suggested that chronic 
synovial inflammation can also be due to hypoxicreperfusion injury mediated by oxygen radicals. ${ }^{54}$ Blake et al recently reported, ${ }^{55}$ in inflammatory synovitis due to several rheumatic conditions, that exercise of the knee is associated with $(a)$ an increase in intra-articular pressure that exceeds the capillary perfusion pressure, $(b)$ a fall in synovial fluid $\mathrm{PO}_{2}$ followed by an increase to suprabasal levels after exercise, $(c)$ a mean reduction of the synovial capillary perfusion of $90 \%$ from baseline values, and $(d)$ a significant rise in lipid peroxidation products and in fluorescent $\mathrm{IgG}$, which indicates free radical damage to the protein. ${ }^{56}$ Free radical modification of IgG may render this molecule antigenic and reactive with rheumatoid factor, thereby promoting immune complexes formation and chronic inflammation. ${ }^{57}$ These results strongly support the hypothesis that chronic synovial inflammation may be mediated by reactive oxygen species generated during exercise induced hypoxiareperfusion. In an attempt to define both the cellular source and the oxygen radical species produced Zweier et al showed that endothelial cells subjected to anoxia-reoxygenation generated superoxide derived hydroxyl radicals, which caused cell damage, and that most of the oxygen radical production was derived from the xanthine oxidase enzyme system. ${ }^{58}$ This system is present in both normal and diseased synovial tissue. ${ }^{59}$ On the other hand, normal human synovial fluid contains no superoxide dismutase, catalase, or glutathione peroxidase to protect against the potential damage produced by oxygen free radicals. ${ }^{60}$

\section{Possible strategies to prevent oxygen free radical reperfusion injury}

From a theoretical point of view two main strategies could be proposed to prevent free radical mediated reperfusion injury: reduction of oxygen radical formation and administration of free radical scavenging agents. Some authors believe that, among the various potential sources of free radicals, xanthine oxidase mediated degradation of purine bases is the most important source, and thus is a potential target for therapeutic intervention. ${ }^{78546162}$ In fact the administration of allopurinol has been shown to protect against haemorrhagic shock induced gastric lesions, ${ }^{63}$ to prevent increased vascular permeability associated with intestinal ${ }^{64}$ and skeletal muscle ischaemia, ${ }^{+0}$ to ameliorate experimental acute pancreatitis, ${ }^{33}$ to protect renal ${ }^{65}$ and liver ${ }^{39}$ function after ischaemia, to reduce myocardial infarct size elicited by coronary artery ligation ${ }^{66-69}$ and reperfusion induced arrhythmias, ${ }^{12} 68$ and to improve the survival rate of skin flaps, ${ }^{70}$ and the survival of dog kidney $^{71}{ }^{72}$ and liver ${ }^{73}$ after transplant.

The mechanism by which allopurinol exerts a protective effect in ischaemia-reperfusion injury is probably multifactorial (Fig. 1). Allopurinol and oxypurinol are scavengers of the highly reactive hydroxyl radicals. ${ }^{62}$ Allopurinol and oxypurinol may also limit superoxide generation through xanthine oxidase inhibition. ${ }^{78}$ In addition, allopurinol and oxypurinol may be converted to their corresponding ribonucleotides by the enzyme hypoxanthine phosphoribosyltransferase. ${ }^{74}$ Allopurinol ribonucleotide causes a $50 \%$ inhibition of 5 '-nucleotidase at a concentration of $10 \mu \mathrm{mol} / \mathrm{l}^{75}$ This may prevent the dephosphorylation of inosine and adenosine monophosphates, thereby facilitating ATP resynthesis. Furthermore, inhibition of xanthine oxidase by allopurinol elicits an increased availability of hypoxanthine that may be salvaged for purine nucleotide synthesis. ${ }^{76} 77$ Enhancement of hypoxanthine reutilisation may save a substantial quantity of energy ${ }^{78}$ as five molecules of ATP are required for inosine monophosphate synthesis via de novo pathway, whereas the conversion of hypoxanthine to inosine monophosphate uses only one molecule of ATP for phosphoribosylpyrophosphate synthesis. This energy sparing pathway may be crucial for adequate organ function after a transplant. ATP recovery after global or regional ischaemia via de novo purine synthesis usually requires one to seven days, ${ }^{79-81}$ and it has been shown that the ability of rat liver to regenerate its ATP and to maintain an adequate energy charge during restoration of hepatic blood flow determines tissue viability and the survival of the animal. ${ }^{82}$ In addition, loss of adenine nucleotides appears to be a good marker of human liver graft damage,${ }^{83}$ and total adenine nucleotide concentration during cold storage has been related to the viability of the graft. ${ }^{83}$ Preliminary experiments in our laboratory have shown that the decrease in dog liver ATP after 30 minutes of partial warm ischaemia was from (mean (SD)) $1.97(0.23)$ to $1.10(0.54) \mu \mathrm{mol} / \mathrm{g}$ of wet tissue $(\mathrm{p}<0.001)$. In contrast, when allopurinol $(50$ $\mathrm{mg} / \mathrm{kg}$ of body weight) was infused for 30 minutes before and during ischaemia the decrease was from $2.22(0.15)$ to $1.96(0.22) \mu \mathrm{mol} / \mathrm{g}$ of wet tissue $(p>0.05)$. The mean decrease in total adenine nucleotides (ATP plus ADP plus AMP) in control dogs at the end of the ischaemic period was -0.82 $\mu \mathrm{mol} / \mathrm{g}$ of wet weight, whereas in dogs pretreated with allopurinol total adenine nucleotides remained essentially unchanged (Mateos FA, Puig JG, Delgado VD, manuscript in preparation). Restoration of adenine nucleotides in the reperfused rat $^{84}$ or $\operatorname{dog}^{85}$ liver after ischaemia was not in- 
fluenced by allopurinol pretreatment. Our results are similar to those reported in ischaemic kidneys ${ }^{86}$ and emphasise the ability of allopurinol to prevent total adenine nucleotide depletion during ischaemia. In other ischaemic settings, however, allopurinol promoted total adenine nucleotide repletion, ${ }^{87}$ probably as a consequence of enhanced hypoxanthine reutilisation.

Inhibition of xanthine oxidase by allopurinol may not be a universal mechanism by which this drug protects ischaemic tissues. Some studies using the rabbit heart, which is devoid of measurable xanthine oxidase activity, showed that allopurinol improves postischaemic left ventricular function ${ }^{88}$ and preserves the myocardial ATP content ${ }^{89}$ This led to the postulation that additional protective mechanisms of allopurinol, in addition to its oxygen radical scavenging effect, ${ }^{62}$ may include an enhanced antioxidant capacity of myocardial tissue. ${ }^{89}$

\section{Future directions}

An increasing body of knowledge has implicated free radical mediated processes in a wide spectrum of different types of human diseases. Among the various potential strategies for reducing oxygen free radical toxicity there is significant evidence that allopurinol exerts a protective effect through several related but not completely understood mechanisms. We are aware of no studies specifically designed to evaluate whether free radical scavenger agents, such as allopurinol, could be beneficial in clinical situations associated with severe tissue damage after significant ischaemia and reperfusion. As we look back on the advances in the treatment of uric acid related diseases we can only hope that similar progress will be made in the elucidation of the intricacies of free radical formation and their interaction with other systems. ${ }^{90}$ Further studies in this area of basic and integrated clinical research should provide fascinating insights into physiological and pathological processes, and would ultimately dictate relevant advances in protecting the body against free radical mediated diseases, such as myocardial ischaemia, inflammatory diseases, or rheumatic conditions.

Supported by grants from Caja de Madrid and Fondo de Investigaciones Sanitarias de la Seguridad Social (88/1161).

Depts of Internal Medicine and Clinical Biochemistry,

'La Paz' Hospital,

Universidad Autónoma,

Madrid, Spain

*Correspondence to Dr Juan García Puig, Costa Brava, 23; $3^{\circ} \mathrm{D}$, 28034 Madrid, Spain.

\section{References}

1 Rundles R W. The development of allopurinol. Arch Intern Med 1985; 145: 1492-503.

2 Krakoff I H. Xanthine oxidase inhibition in the management of hyperuricemia in leukemias and lymphomas. Arthritis Rheum 1965; 8: 896-8.

3 Krakoff I H, Meyer R L. Prevention of hyperuricemia in leukemia and lymphoma: use of allopurinol, a xanthinc oxidase inhibitor. JAMA 1965; 193: 89-94.

4 DeConti R C, Calabresi P. Use of allopurinol for prevention and control of hyperuricemia in patients with neoplastic disease. $N$ Engl J Med 1966; 274: 481-6.

5 Ettinger B, Tang A, Citron J T, Livermore B, Williams $\mathrm{T}$. Randomized trial of allopurinol in the prevention of calcium oxalate calculi. $N$ Engl J Med 1986; 315: 1386-9.

6 Singer J Z, Wallace S L. The allopurinol hypersensitivity syndrome: unnecessary morbidity and mortality. Arthritis Rheum 1986; 29: 82-7.

7 McCord J M. Oxygen-derived free radicals in postischemic tissue injury. $N$ Engl $J$ Med 1985; 312: 159-63.

8 Granger D N, Höllwarth $M$ E, Parks D A. Ischemiareperfusion injury: role of oxygen-derived frec radicals. Acta Physiol Scand [Suppl] 1986; 548: 47-63.

9 Parks D A, Granger D N. Xanthine oxidase: biochemistry, distribution and physiology. Acta Physiol Scand /Suppl] 1986; 548: $87-99$.

10 McCord J M, Fridovich I. The reduction of cytochrome C by milk xanthine oxidase. J Biol Chem 1968; 243: 5753-60.

11 Jones C E, Crowell J W. Smith E E. Significance of increased blood uric acid following extensive hemorrhage. Am J Physiol 1968; 214: $1374-7$.

12 DeWall R R, Vasko K A, Stanley E L, Kezdi P. Responses d the ischemic myocardium to allopurinol. Am Heart J 1971; 82\% 362-70.

13 Kugler G. Myocardial release of inosine, hypoxanthine and lactate during pacing-induced angina in humans with coronary artery disease. European Journal of Cardiology 1979; 9: 227-40.

14 Della Corte E, Stirpe F. The regulation of rat liver xanthine oxidase: involvement of thiol groups in the conversion of the enzyme activity from dehydrogenase (type D) into oxidase (type O) and purification of the enzyme. Biochem J 1972; 126: $739-45$.

15 Porras A G, Olson J S. Palmer G. The reaction of reduced xanthine oxidase with oxygen: kinetics of peroxide and superoxide formation. J Biol Chem 1981; 256: 9096-103.

16 Halliwell B, Gutteridge J M C. Oxygen toxicity, oxygen radicals, transition metals and discase. Biochem $J$ 1984; 219: 1-14.

17 Blake D R, Lunec J, Winyard P, Brailsford S. Iron, free radicals and chronic inflammation. In: Moll $\mathbf{J}$ M H. Sturrock $R$ D. eds. Recent advances in rheumatology. Vol. 4. Edinburgh: Churchill Livingstone, 1986: 21-36.

18 Blake D R, Bacon P A. Synovial fluid ferritin in rheumatoid arthritis: An index or cause of inflammation? $\mathrm{Br}$ Med $J 1981$; 282: 189 .

19 Blake D R, Gallagher P J, Pctter A R, Bell M J, Bacon P A. The effect of synovial iron on the progression of rheumatic disease. Arthritis Rheum 1984; 27: 495-501.

20 Del Maestro R F. An approach to free radicals in medicine and $N$ biology. Acta Physiol Scand [Suppl] 1980; 492: 153-68.

21 Cross C E. Oxygen radicals and human disease. Ann Intern Med 1987: 107: 526-45.

22 Boveris A. Mitochondrial production of superoxide radical and hydrogen peroxide. Adv Exp Med Biol 1977; 78: 67-82.

23 Babior B M. Oxidants from phagocytes: agents of defense and destruction. Blood 1984; 64: 959-66.

24 Kuthan $\mathrm{H}$, Ullrich $\mathrm{V}$. Oxidase and oxygenase function of the microsomal cytochrome P-450 monooxygenase system. Eur $J$ Biochem 1982; 126: 583-8. 
25 Demopoulos H B, Flamm E S, Pietronigro D D, Seligman M L. The free radical pathology and the microcirculation in the major central nervous system disorders. Acta Physiol Scand [Suppl] 1980; 492: 91-119.

26 Shlafer M, Kane P F, Wiggins V Y, Kirsh M M. Possible role for cytotoxic oxygen metabolites in the pathogenesis of cardiac ischemic injury. Circulation 1982; 66 (suppl I): 185-92.

27 Peterson D A, Asinger R W, Elsperger K J, Homans D C Eaton J W. Reactive oxygen species may cause myocardial reperfusion injury. Biochem Biophys Res Commun 1985; 127: 87-93.

28 Simpson P J, Lucchesi B R. Free radicals and myocardial ischemia and reperfusion injury. J Lab Clin Med 1987; 110: 13-30.

29 Cochran T, Skpanko J, Moore C, Saik R. Dimethylsulfoxide protection against gastric stress ulceration. Curr Surg 1983; 40: 435-7.

30 Granger D N, Rutili G, McCord J M. Superoxide radicals in feline intestinal ischemia. Gastroenterology 1981; 81: 22-9.

31 Parks D A, Bulkley G B, Granger D N. Role of oxygen-derived free radicals in digestive tract diseases. Surgery 1983; 94: 415-22.

32 Sanfey H, Bulkley G B, Cameron J L. The role of oxygenderived free radicals in the pathogenesis of acute pancreatitis. Ann Surg 1984; 200: 405-12.

33 Sanfey H, Sarr M G, Bulkley G B, Cameron J L. Oxygenderived free radicals and acute pancreatitis: a review. Acta Physiol Scand [Suppl] 1986; 548: 109-18.

34 Wisner J, Green D, Fenell L, Renner I. Evidence for a role of oxygen derived free radicals in the pathogenesis of caerulein induced acute pancreatitis in rats. Gut 1988; 29: 1516-23.

35 Green C J, Healing G, Lunec J, Fuller B J, Simpkin S. Evidence of free-radical-induced damage in rabbit kidneys after simple hypothermic preservation and autotransplantation. Transplantation 1986; 41: 161-5.

36 Siems W, Mielki B, Muller M, Heumann C, Rader L, Gerber G. Status of glutathione in the rat liver. Enhanced formation of oxygen radicals at low oxygen tension. Biomed Biochim Acta 1983; 42: 1079-89.

37 Marubayasi S, Dohi K, Ezaki H, Yamada K, Kawasaki T Preservation of ischemic liver cell-damage by coenzyme $Q_{10}$. Transplant Proc 1983; 15: 1297-9.

38 Marubayashi S, Dohi K, Yamada K, Kawasaki T. Changes in the levels of endogenous coenzyme $\mathrm{Q}$ homologs, $\alpha$-tocopherol, and glutathione in the rat liver after hepatic ischemia and reperfusion, and effect of pretreatment with coenzyme $Q$. Biochemica Biophysica Acta 1984; 797: 1-9.

39 Adkinson D. Höllwarth M E, Benoit J N, Parks D A. McCord J M, Granger D N. Role of free radicals in ischemia-reperfusion injury to the liver. Acta Physiol Scand /Suppl] 1986; 548: 101-8.

40 Korthuis R J, Granger D N, Townsley M I. Taylor A E. The role of oxygen-derived free radicals in ischemia-induced increases in canine skeletal muscle vascular permeability. Circ Res 1985; 57: 599-609.

41 Manson P N, Anthenelli R N, Im M J. Bulkley G B. Hoopes $\mathrm{J} E$. The role of oxygen-free radicals in ischemic tissue injury in island skin flaps. Ann Surg 1983; 198: 87-90.

42 Grogaard B, Parks D A, Granger D N, McCord J M, Forsberg $J$ D. Effects of ischemia and oxygen radicals on mucosal albumin clearance in intestine. Am J Physiol 1982; 242: G448-54.

43 Saugstad O D. Hallman M, Abraham J L. Epstein B. Cochrane C. Gluck L. Hypoxanthine and oxygen induced lung injury: A possible basic mechanism to tissue damage? Pediatr Res 1984; 18: $501-4$.

44 Abb-Elfattah A S, Jessen M E, Lekven J, Doherty N E, Brunsting L A, Wechsler A S. Myocardial reperfusion injury. Role of myocardial hypoxanthine and xanthine in free radicalmediated injury. Circulation 1988; 78 (suppl III): III-224-35.
45 Burton K P, McCord J M, Ghai G. Myocardial alterations due to free radical generation. Am J Physiol 1984; 246: H776-83.

46 Shlafer M, Kane P F, Kirsh M M. Superoxide dismutase plus catalase enhance the efficacy of hypothermic cardioplegia to protect the globally ischemic, reperfused heart. $J$ Thorac Cardiovasc Surg 1982; 83: 830-9.

47 Stewart J R, Blackwell W H, Crute S L, Loughlin V, Hess M L, Greenfield L J. Prevention of myocardial ischemia/reperfusion injury with oxygen free-radical scavengers. Surgery Forum 1982; 33: 317-20.

48 Casale A S, Bulkley G B, Bulkley B H, Flaherty J T, Gott V L, Gardner T J. Oxygen free-radical scavengers protect the arrested, globally ischemic heart upon reperfusion. Surgery Forum 1983; 34: 313-6.

49 Zweier J L, Flaherty J T, Weisfeldt M L. Direct measurement of free radical generation following reperfusion of ischemic myocardium. Proc Natl Acad Sci USA 1987; 84: 1404-7.

50 Garlick P B, Davies M J, Hearse D J. Slater T F. Direct detection of free radicals in the reperfused rat heart using electron spin resonance spectroscopy. Circ Res 1987; 61: 757-60.

51 Kramer J H, Arroyo C M, Dickens B F, Weglicki W B. Spintrapping evidence that graded myocardial ischemia alters postischemic superoxide production. Journal of Free Radicals in Biology and Medicine 1987; 3: 153-9.

52 Arroyo C M, Kramer J H, Dickens B F, Weglicki W B. Identification of free radicals in myocardial ischemia/reperfusion by spin trapping with nitrone DMPO. FEBS Lett 1987; 221: 101-4.

53 Bolli R, Patel B S, Jeroudi M O, Lai E K, McCay P B. Demonstration of free radical generation in 'stunned' myocardium of intact dogs with use of the spin trap $\alpha$-phenyl $N$-tertbutyl nitrone. J Clin Invest 1988; 82: 476-85.

54 Woodruff T, Blake D R, Freeman J, Andrews F J, Salt P, Lunec $\mathrm{J}$. Is chronic synovitis an example of reperfusion injury? Ann Rheum Dis 1986; 45: 608-11.

55 Blake D R, Unsworth J, Outhwaite J M, et al. Hypoxiareperfusion injury in the inflamed human joint. Lancet 1989; i: 289-93.

56 Blake D R, Allen R E, Lunec J. Free radicals in biological systems-a review oriented to inflammatory processes. $\mathrm{Br} \mathrm{Med}$ Bull 1987; 43: 371-85.

57 Lunec J, Blake D R, McCleary S J, Brailsford S, Bacon P A. Self perpetuating mechanisms of immunoglobulin $G$ aggregation in rheumatoid inflammation. J Clin Invest 1985; 76: 2084-90.

58 Zweier J L, Kuppusamy P, Lutty G A. Measurement of endothelial cell free radical injury in postischemic tissues. Proc Natl Acad Sci USA 1988; 85: 4046-50.

59 Allen R E, Duthwaite J M, Morris C J, Blake D R. Xanthine oxidoreductase is present in human synovium. Ann Rheum Dis 1987; 46: 843-5.

60 Blake D R. Hall N D, Treby D A, Halliwell B, Gutteridge J M C. Protection against superoxide and hydrogen peroxide in synovial fluid from rheumatoid patients. Clin Sci 1981; 61: 483-6.

61 Parks D A, Bulkley G B, Granger D N. Role of oxygen free radicals in shock, ischemia, and organ preservation. Surgery 1983; 94: 428-32.

62 Moorhouse P C, Grootveld M. Halliwell B, Quinlan J G, Gutteridge J M C. Allopurinol and oxypurinol are hydroxyl radical scavengers. FEBS Lett 1987; 213: 23-8.

63 Itoh M. Guth P. Superoxide radicals play a role in hemorrhagic shock induced gastric lesions in the rat. Gastroenterology 1984; 86: 1122 .

64 Parks D A, Granger D N. Ischemia-induced vascular changes: role of xanthine oxidase and hydroxyl-radicals. Am J Physiol 1983; 245: G285-9.

65 Paller M S, Hoidal J R, Ferris T F. Oxygen free radicals in 
ischemic acute renal failure in the rat. $J$ Clin Invest 1984; 74: 1156-64.

66 Akizuki S, Yoshida S, Chambers D E, et al. Infarct size limitation by the xanthine oxidase inhibitor, allopurinol, in closed-chest dogs with small infarcts. Cardiovasc Res 1985; 19: 686-92.

67 Werns S W, Shea M J, Mitsos S E, et al. Reduction of the size of infarction by allopurinol in the ischemic-reperfused canine heart. Circulation 1986; 73: 518-24.

68 Hearse D J, Manning A S, Downey J M, Yellon D M. Xanthine oxidase: A critical mediator of myocardial injury during ischemia and reperfusion? Acta Physiol Scand [Suppl] 1986; 548: 65-78.

69 Kingma J G Jr, Dennis A R, Hearse D J, Downey J M, Yellon D M. Limitation of infarct size for 24 hours by combined treatment with allopurinol plus verapamil during acute myocardial infarction in the dog. Circulation 1987; Suppl V: V-25-33.

70 Im M J, Shen W H, Pak C J, Manson P N, Bulkley G B, Hoopes J E. Effect of allopurinol on the survival of hyperemic island skin flaps. Plast Reconstr Surg 1984; 73: 276-8.

71 Owens M L, Lazarus H M, Wolcott M W, Maxwell J G, Taylor B. Allopurinol and hypoxanthine pretreatment of canine kidney donors. Transplantation 1974; 17: 424-7.

72 Toledo-Pereyra L H, Simmons R L, Najarian J S. Effect of allopurinol on the preservation of ischemic kidneys perfused with plasma or plasma substitutes. Ann Surg 1974; 180: 780-2.

73 Toledo-Pereyra L H, Simmons R L, Najarian J S. Factors determining successful liver preservation for transplantation. Ann Surg 1975; 181: 289-98.

74 Nelson D, Bugge C, Crasny H, Ellion G. Formation of nucleotides of $\mathrm{G}-{ }^{14} \mathrm{C}$ allopurinol and $\mathrm{G}-{ }^{14} \mathrm{C}$ oxypurinol in rat tissues and effect on uridine nucleotide pools. Biochem Pharmacol 1973; 22: 2003-22.

75 Fox I, Marchant P. Purine catabolism in man: inhibition of 5 phosphomonoesterase activities from placental microsomes. Can J Biochem 1976; 54: 1055-60.

76 Edwards N L, Recker D, Airozo D, Fox I H. Enhanced purine salvage during allopurinol therapy: an important pharmacologic property in humans. $J$ Lab Clin Med 1981; 98: 673-83.

77 Mateos F A, Puig J G, Jiménez M L, Fox I H. Hereditary xanthinuria: evidence for enhanced hypoxanthine salvage. $J$ Clin Invest 1987; 79: 847-52.
78 Puig J G, Jiménez M L, Mateos F A, Fox I H. Adenine nucleotide turnover in hypoxanthine-guanine phosphoribosyltransferase (HGPRT) deficiency: evidence for an increased contribution of purine biosynthesis de novo. Metabolism 1989; 38: $410-8$

79 Vary T C, Angelakos E T, Schaffer S W. Relationship between adenine nucleotide metabolism and irreversible ischemic tissue in isolated perfused rat heart. Circ Res 1979; 45: 218-24.

80 Reimer K A, Hill M L, Jennings R B. Prolonged depletion of ATP and the adenine nucleotide pool due to delayed resynthesis of adenine nucleotides following reversible myocardial ischemic injury in dogs. $J$ Mol Cell Cardiol 1981; 13: 229-39.

81 Swain J L, Sabina R L, McHale P A, Greenfield J C Jr, Holmes $\mathrm{E}$ W. Prolonged myocardial nucleotide depletion after ischemia in the open-chest dog. Am J Physiol 1982; 242: H818-26.

82 Marubayashi S, Takenaka M, Dohi K, Ezaki H, Kawasaki T. Adenine nucleotide metabolism during hepatic ischemia and subsequent blood reflow periods and its relation to organ viability. Transplantation 1980; 30: 294-6.

83 Kamüke W, Burdelski M, Steinhoff G, Ringe B, Lauchart W, Pichlmayr R. Adenine nucleotide metabolism and its relation to organ viability in human liver transplantation. Transplantation 1986; 45: 138-43.

84 Kamiike W, Watanabe F, Hashimoto $T$, et al. Changes in cellular levels of ATP and its catabolites in ischemic rat liver. $J$ Biochem 1982; 91: 1349-56.

85 Nordström G, Seeman T, Hasselgren P O. Beneficial effect of allopurinol in liver ischemia. Surgery 1985; 97: 679-83.

86 Cunningham $S \mathrm{~K}$, Keaveny $\mathrm{T} V$, Fitzgerald $P$. Effect of allopurinol on tissue ATP, ADP and AMP concentrations in renal ischaemia. Br J Surg 1974; 61: 562-5.

87 Lasley R D, Ely S W, Berne R M, Mentzer R M Jr. Allopurino enhanced adenine nucleotide repletion after myocardia ischemia in the isolated rat heart. J Clin Invest 1988; 81: 16-20

88 Grum C M, Ketal L H, Myers C L, Shlafer M. Purine efflux after cardiac ischemia: relevance to allopurinol cardioprotection: Am J Physiol 1987; 252: H368-73.

89 Godin D V, Bhimji S. Effects of allopurinol on myocardial ischemic injury induced by coronary artery ligation and reperfusion. Biochem Pharmacol 1987; 36: 2101-7.

90 Southorn P A, Powis G. Free radicals in medicine. II. Involvement in human disease. Mayo Clin Proc 1988; 63: 390-408. 